\title{
The Effects of Social Capital on Innovation Performance: From Complex Adaptive System Perspective
}

\author{
Shenglan Huang ${ }^{1} \&$ Zhi Chen $^{1}$ \\ ${ }^{1}$ Shanghai Lixin University of Accounting and Finance, China \\ Correspondence: Zhi Chen, Shanghai Lixin University of Accounting and Finance, China. E-mail: \\ zhichen@mail.ustc.edu.cn
}

Received: January 11, 2016

Accepted: January 24, 2017 Online Published: February 22, 2017

doi:10.5539/ijbm.v12n3p191

URL: https://doi.org/10.5539/ijbm.v12n3p191

\begin{abstract}
The effects of organizational social capital on organizational innovation have attracted the bulk of attention in recent innovation literature. However, few studies have investigated the effects of organizational social capital on innovation performance from the complex adaptive system (CAS) perspective. Based on the CAS perspective, this paper simulates how organizations in manufacturing and service industries seek higher innovation performance on the rugged fitness landscape, which is determined by the complexity of the six components of organizational social capital. Data are collected from 271 firms including 129 manufacturing and 142 service firms. Empirical results indicate that except for inter-organizational coordination, the other five components of organizational social capital significantly affect innovation performance; and their effects vary between manufacturing and service organizations. Further, simulation results demonstrate that after adaptive evolution, the average innovation performance in manufacturing organizations is higher than that in service organizations.
\end{abstract}

Keywords: Complex adaptive systems, Social capital, Innovation, $N K$ model

\section{Introduction}

Innovation is crucial for attaining competitive advantages for business organizations (Naranjo-Valencia et al., 2011). Recently, there is a wide feeling of agreement that innovation performance depends not only on market or technological determinants, also on organizational social capital through networks of interaction and learning (Pérez-Luño et al., 2011; Martínez-Cañas et al., 2012). Although there are several empirical and theoretical studies on the relationship between organizational social capital and innovation performance (Jamali et al., 2011), research on the relationship between organizational social capital and innovation performance from the CAS perspective is limited.

Business organization have been understood as a CAS. This argument has been discussed by Levinthal and Warglien (1999) showing that the attributes that determine fitness for an organization may comprise the elements of its business strategy, its human resource policy and manufacturing system, and its self-organizing processes depend upon the interdependencies among the attributes. A few further studies have applied the CAS perspective to study organizational innovation (Giannoccaro, 2011). For example, Frenken (2001) posited that the interdependencies between technological artefacts can lead technologies to lock-in into local optima on a rugged fitness landscape. Following the focus of the literature on business organization as a CAS, we aim to investigate that in terms of adaptive evolution, how business organizations seek higher innovation performance.

To address this issue, we draw from recent work on the methodologies of CAS, particularly Kauffman's (1993) $N K$ model. The $N K$ model takes into account the number of components of the system and the complexity of the components, respectively, denoted by $N$ and $K$. On the one hand, the $N K$ model is conducive not only for understanding past and current situations, also for providing a landscape view of possible paths for future situations (Frenken, 2006; Ganco \& Hoetker, 2009). On the other hand, this method enables elaboration and exploration through computational experimentation to observe any output changes; computational experimentation can modify the initial values of the parameters in each run (Giannoccaro, 2011). The $N K$ model is thus well-suited to study CAS. However, the application of the $N K$ model has two shortages. First, although scholars have applied the $N K$ model to investigate organizational learning (Dosi et al., 2011), organizational dynamics (Valente et al., 2011), leadership (Goldstein et al., 2007), and strategy management (Ganco \& Hoetker, 2009), few scholars have adopted the $N K$ model to analyze organizational innovation. Second, most of previous 
studies theoretically apply the $N K$ model to simulate organizational behaviors or processes (Frenken, 2006). Although a theoretical model has the advantage of dealing with uncertainty and enhancing computational productivity in CAS (Ganco \& Hoetker, 2009), theoretical model can not directly reflect real situations like empirical research. Therefore, some scholars have called for more research that simulates organizational behaviors or processes in real situations resulting from empirical research (Fan \& Lee, 2012).

In sum, to fill the two abovementioned shortages, the current research combines the survey method with the $N K$ model to investigate the effects of organizational social capital on innovation performance from the CAS perspective. Specifically, we first identify six components of organizational social capital, namely, inter-organizational coordination (IOC), inter-functional coordination (IFC), inter-organizational trust (IOT), customer orientation (CO), shared goal (SG), and shared norms (SN). Then, we conduct a survey to empirically investigate the effects of the six components in improving innovation performance. After that, the survey results would be transferred as the input parameters of the $N K$ model. By using the $N K$ model, we simulate how organizations seek higher innovation performance on a more realistic and precise rugged fitness landscape determined by the complexity of the six components of organizational social capital.

Furthermore, it is suggested that different industries have different business objectives, interests, models, and environments, all of which affects the development of organizational innovation performance (Sørensen \& Stuart, 2000). Research on organizational innovation in different industrial contexts has found that the development of organizational innovation varies with the type of industry (Weerawardena et al., 2006). Therefore, we further explore whether or not the adaptive evolutions of innovation performance are different between manufacturing and service organizations.

\section{The Elements of Organizational Social Capital and Their Interdependencies}

Organizational social capital is defined as the aggregate of resources embedded within, available through, and derived from the network of relationships possessed by an organization (Nahapiet \& Ghoshal, 1998). It has been widely divided to three main dimensions: structural capital, relational capital, and cognitive capital (Butler \& Purchase, 2008). Structural capital refers to the overall pattern of connections between actors, that is, who you reach and how you reach them (Pérez-Luño et al., 2011). Relational capital refers to the quality or strength of social ties, which is usually a reflection of the duration of the ongoing relationship, the extent of emotional intimacy, and the frequency of reciprocal behaviors (Nahapiet \& Ghoshal, 1998). Cognitive capital encompasses the resources providing shared representations, interpretations, and systems of meaning among parties (Nahapiet $\&$ Ghoshal, 1998). However, the complexity of organizational social capital elements acquires a deeper and more thorough investigation, because the three dimensions are rather high level such that we can not appreciate specific forms of organizational social capital in the matter of innovation, primarily trust, norms, and network ties (Landry et al., 2002). Given that the major characteristic of innovative processes is balancing contrary forces or complementary opposites that are interconnected and interdependent (Fan \& Lee, 2012), we identify two fundamental characteristics for each category of structural capital, relational capital, and cognitive capital (see Figure 1).

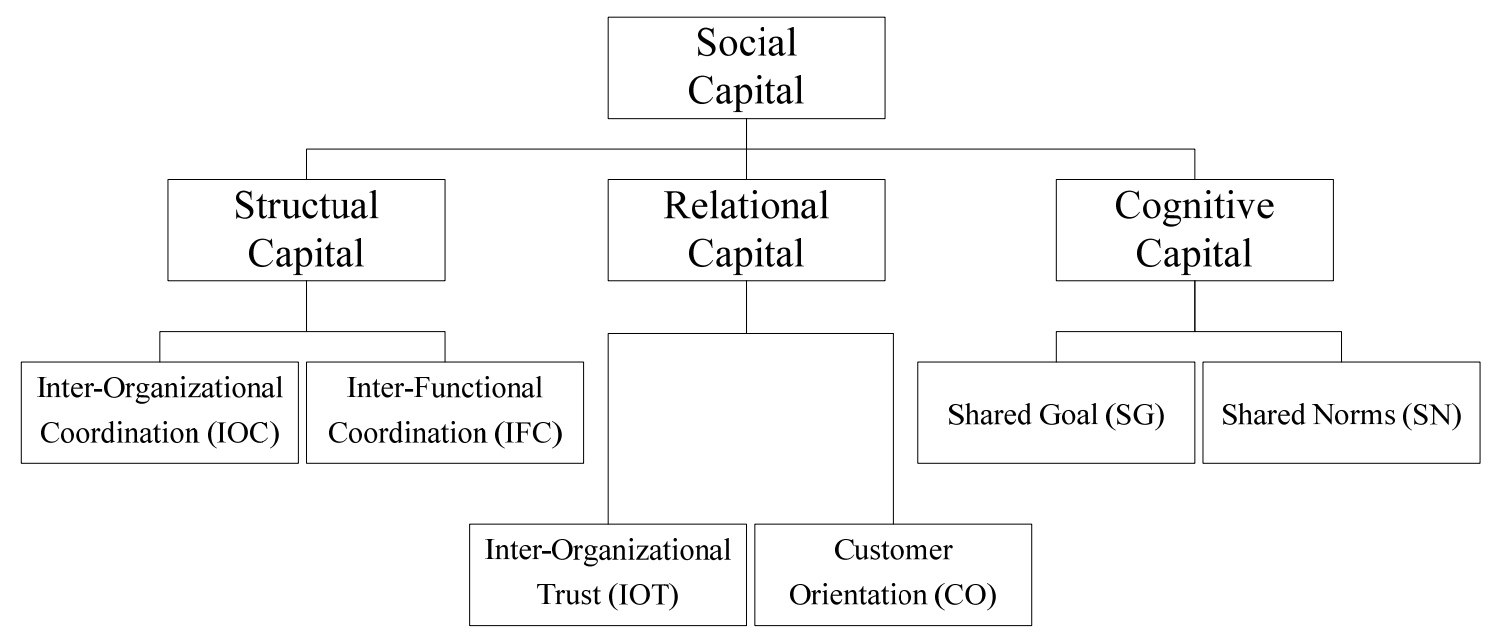

Figure 1. Social capital components 


\subsection{Structural Capital: IFC and IOC}

The pair of IFC and IOC examines the internal and external integration aspects of structural capital. It is generally accepted that the structural dimension of network consists of ties between functional departments in a firm and also between firms (Kaasa, 2009). IFC refers to a firm's ability to utilize interdependent resources in a coordinated manner through effective communication, integration, and exchange, across many functional departments (Narver \& Slater, 1990). Different functional units within a firm need to be coordinated in the collection, sharing, and analysis of customer and competitor market information, such as customer preferences, the strengths and weaknesses of competitors, and the response to market changes ( $\mathrm{Li}$ et al., 2010). Collective learning from multiple sources (information, skills, and knowledge) is believed to be a source of innovative capability for firms (Hausera et al., 2007). However, there is much competition among organizations for scarce resources. It is increasingly suggested that organizations can not innovate without IOC. Taylor and Levitt (2005) identified several characteristics of inter-organizational knowledge flows which will impact the diffusion of innovations. Moreover, strong involvement in IOC benefits the diversity of institutional sources of innovation (Powell, 1996). Further, improvement in social interaction ties between firms could create a store of trust, goodwill and reciprocity which, in turn, can be directed by the firm to generate benefits such as reduced costs, greater capacity to innovate, and reduced new product development time (Carey et al., 2011). Therefore, we propose the following hypothesis.

\section{H1: IFC and IOC are both positively related to innovation performance.}

\subsection{Relational Capital: IOT and CO}

IOT and CO are critical attributes for relational capital. There is mounting evidence suggesting that when trust is built up between organizations, they are more willing to engage in cooperative activity through which further trust can be generated (Kaasa, 2009). Accordingly, IOT can influence innovative activity through many mechanisms, such as the reduction of the need for formal monitoring and bargaining over agreement (Tamaschke, 2003), valuable knowledge sharing (Inkpen \& Tsang, 2005), and less risk averse encouraging investors to invest more in R\&D projects (Akçomak \& ter Weel, 2006). Different studies have suggested that the closeness or connectivity of social relationship between two parties allows firms to benefit from knowledge distributed and accumulated by close contacts and interactions, thereby, to further achieve favorable innovation (Huang et al., 2009). For instance, Dyer and Nobeoka (2000) demonstrated Toyota and its suppliers' highly interconnected networks which create a strong coordinating rules motivate members to openly share valuable knowledge and engage in multidirectional knowledge flows and innovation. Furthermore, $\mathrm{CO}$ indicates whether a firm has sufficient knowledge of its targeted customers to generate superior customer value ( $\mathrm{Li}$ et al., 2010). Customer-oriented firms with robust customer relationships are good at identifying market opportunities, thereby advancing their innovative activities (Narver \& Slater, 1990). Scholars have argued that firms with high CO often have higher technological innovation performance than firms with low CO (Li et al., 2010). Therefore, we hypothesize:

\section{H2: IOT and CO are both positively related to innovation performance.}

\subsection{Cognitive Capital: $S G$ and $S N$}

Cognitive capital coming with many attributes could be collected into two clusters: SG and SN. SG embodies the collective goals and aspirations of the organizations of an intra-firm network (Inkpen \& Tsang, 2005). In this case, organizations with SG will seek harmony, balance, equity, mutual support and even strategic alliance as a means for maximizing joint value (Willcocks \& Choi, 1995). For example, SG and a set of common values help partner firms enhance cooperation and knowledge sharing which is conducive for value creation (Chow \& Chan, 2008). Moreover, Das and Teng (2001) suggested that SG could reduce relational risk and performance risk of partner firms by output control and social control, which in turn will benefit organizational innovation. SN encompass secular norms like professional standards and codes of behavior (Fukuyama, 1995). Just as important as SG, SN should be established along with forging SG. If SN are incongruent, interactions between partner organizations can be expected to lead to misinterpretation of events and conflict, resulting in negative effects on value creation and performance (Inkpen \& Tsang, 2005). The literature has demonstrated that SN could facilitate the understanding of parties' thinking processes, activates information and knowledge diffusion, and fosters supports for innovative activities (De Carolis \& Saparito, 2006). Hence, we propose the following hypothesis.

\section{H3: $S G$ and $S N$ are both positively related to innovation performance.}

In sum, we have expected that the six components of organizational social capital have significant influence on innovation performance. Based on the CAS perspective, we shall use the $N K$ model to simulate the adaptive 
evolution of innovation performance on the rugged landscape, which is determined by the complexity of the six components of organizational social capital. Therefore, the next section shall introduce the $N K$ model.

\section{The NK model}

The $N K$ model was developed by Kauffman (1993) to model biological evolution. It describes a system by a string of $N$ elements $(i=1, \ldots, N)$, each of which in one of two possible states. The two states of a element are labeled by integers " 0 ", " 1 ". Then, each string $x$ is described by $x_{1} x_{2} \cdots x_{N}$ and is part of a possibility set $X$, for which holds:

$$
x \in X, x=x_{1} x_{2} \cdots x_{N} \text { and } x_{i} \in\{0,1\} .
$$

In the $N K$ model, Kauffman (1993) expressed the complexity of the consisting elements by one parameter $K$, which stands for the number of elements that affect the functioning of each element. The value of $K$ can form a rugged fitness landscape that allows path searching for optimization and strategy planning (Frenken, 2001). After that, system fitness performance is derived as the mean value of the fitness performance of elements:

$$
\phi(x)=\left[\sum_{i=1}^{N} \phi_{i}(x)\right] / N,
$$

where $\phi_{i}(x)$ is the fitness performance of element $i$.

Hence, the fitness performance of element $i$ depends not only on the specific state but also on how the other elements interacting with it are resolved (Giannoccaro, 2011). When $K=0, \phi_{i}(x)$ is independent from the other elements; when $K=N-1, \phi_{i}(x)$ depends on all the remaining elements.

The mapping from choice configurations to system fitness performance is called fitness landscape. The goal of agent search is to reach the highest peak of the landscape, that is, to identify the configuration choice that yields the highest system fitness performance (Giannoccaro, 2011). The agent is, thus, engaged in adaptive walking through the landscape in search of the global optimum. We refine the $N K$ model by considering the extensions of the non-binary alleles, non-integer degree of complexity, and unequal weights to ensure that the model can be utilized with the survey method to study organizational innovation.

First, Kauffman (1993) adopted the $N K$ model to study the evolutionary process of a genetic system by idealizing the activity of any gene as "on" or "off" denoted by 0 or 1 . However, the binary state of each element becomes inadequate for empirical study because the states of the characteristics can be present or absent. The binary states of elements need to be generalized to $A$ characteristics, where $A$ is an integer larger than 2 .

Second, the $N K$ model also assumes that (i) if the interdependency exists between two elements, a value of 1 is assigned; otherwise, a value of 0 is assigned, and (ii) the functioning of each element is influenced by $K$ other elements. $K$, which measures the interdependency of an element with all its neighbors, is therefore an integer between 0 and $N-1$. In fact, the interdependency between two characteristics is not simply "existent" or "nonexistent." The value of the interdependency between two characteristics should be modified into a fraction between 0 and 1 . The value of the interdependency of one characteristic with all the other characteristics is then modified as non-integer value $K$ between 0 and $N-1$. This non-integer value sums up the degree of interdependency of the characteristic with every other characteristic.

Lastly, system fitness performance in the $N K$ model is derived as the mean value of the fitness of the elements. However, the contributions of different elements may vary. This condition provides unequal attribute weights to the elements in known information or empirical analysis.

\section{Research design, data, and analysis}

\subsection{Sample and Measures}

Our study focused on the industries with high requirements of organizational innovation to compare organizational innovation performance between manufacturing and service organizations. The manufacturing and service industries played a fundamental role in the Chinese economy. Accordingly, the manufacturing and service organizations were selected as respondents. For each organization, the questionnaire was sent to one senior executive as the representation of the organization. Although the use of a single respondent may not be ideal for organization-level studies, this approach is common among recent empirical studies (Stock et al., 2007).

We first sent out 400 questionnaires. 283 responses were identified, with the response rate of $70.8 \%$. After discarding the missing values, a total of 271 usable and valid responses were used in this study. Table 1 showed the demographic information of the sample. 
Table 1. Sample demographic

\begin{tabular}{lll}
\hline Demographic characteristics & N & Percentage \\
\hline Industry type & & \\
Manufacturing & 129 & $47.6 \%$ \\
Service & 142 & $52.4 \%$ \\
Number of employees & & \\
49 or fewer & 102 & $37.6 \%$ \\
$50-99$ & 91 & $33.6 \%$ \\
$100-249$ & 52 & $19.2 \%$ \\
250 or more & 26 & $9.6 \%$ \\
\hline
\end{tabular}

To measure our constructs, we adopted the existing validated and well-tested scales in the extant literature. All the constructs used in the questionnaire were measured using multi-item scales (five-point Likert-type scales, ranging from "strongly disagree" to "strongly agree").

Inter-organizational coordination was tested with five items from Stock and Tatikonda (2008). These items primarily investigated the communication, coordination and cooperation between the source and partner firms. A sample items is: "Our organization has widely coordinate with our business partners."

Inter-functional coordination was measured by five items, that were adopted from Narver and Slater (1990). These items described a firm's ability to utilize interdependent resources in a coordinated manner through effective communication, integration, and exchange, across many functional departments. A sample item is: "Information about customers is freely communicated throughout our organization."

Inter-organizational trust was measured by two items that were developed from $\mathrm{Wu}$ (2008). This scale was designed to capture an organization's confidence in its business partners not behaving opportunistically. A sample item is: "We never worry that our business partners will take advantage of us."

Customer orientation was measured by six items from Narver and Slater (1990). These items refer to the degree of putting the customer's interest first. A sample item is: "We closely monitor and assess our level of commitment in serving customer's needs."

Shared goals was measured by three items adapted from Chow and Chan (2008). The measurement described the extent to which the focal firm and business partners hold together. A sample item is: "Our organization and business partners always agree on what is important at work."

Shared norms was measured by six items adapted from Lai (2009). Shared norms was measured about what is appropriate or inappropriate behavior in the relationship between the focal organization and business partners. A sample item is: "We are committed to improvements that may benefit the relationship as a whole, and not only individual parties."

Innovation performance is measured by seven items adopted from Ibarra (1993). These items consist of two dimensions, namely, technical innovation and administrative innovation. Specifically, technical innovation is assessed by three items to describe the extent to which the firm develops new technologies, and facilitates new processes to improve quality and lower cost. A sample item is: "Our organization enhances the development of new technologies." Administrative innovation was assessed by four items to measure the extent of responsiveness to environmental dynamism, and innovative administration about planning procedures, and process control systems. A sample item is: "Our organization flexibly responds to environmental changes."

\subsection{Data Analysis and Survey Results}

Confirmatory factor analysis was performed to assess the reliability and validity of the multi-item measurement scale. Table 2 showed composite reliability and discriminant validity.

Table 2 . The reliability and validity results

\begin{tabular}{llll}
\hline Variables & Loading & Cronbach $\boldsymbol{\alpha}$ & Composite reliability \\
\hline Inter-organizational Coordination & $0.64-0.84$ & 0.90 & 0.88 \\
Inter-functional Coordination & $0.75-0.80$ & 0.83 & 0.86 \\
Inter-organizational Trust & $0.71-0.88$ & 0.85 & 0.90 \\
\hline
\end{tabular}




\begin{tabular}{llll}
\hline Customer Orientation & $0.74-0.82$ & 0.85 & 0.89 \\
Shared Goal & $0.78-0.84$ & 0.91 & 0.90 \\
Shared Norms & $0.81-0.89$ & 0.90 & 0.92 \\
Innovation Performance & $0.75-0.86$ & 0.82 & 0.88 \\
\hline
\end{tabular}

Table 3 demonstrated that all study variables are significantly correlated, and all the components of organizational social capital are rather strongly correlated with innovation performance.

Table 3. Means, standard deviations, and correlations

\begin{tabular}{lllllllll}
\hline & Mean & s.d. & $\mathbf{1}$ & $\mathbf{2}$ & $\mathbf{3}$ & $\mathbf{4}$ & $\mathbf{5}$ & $\mathbf{6}$ \\
\hline 1. Inter-Organizational Coordination & 3.24 & 0.90 & & & & & & \\
2. Inter-Functional Coordination & 3.48 & 0.70 & $0.53^{* *}$ & & & & & \\
3. Inter-Organizational Trust & 3.55 & 0.69 & $0.51^{* *}$ & $0.44^{* *}$ & & & & \\
4. Customer Orientation & 3.78 & 0.75 & $0.50^{* *}$ & $0.54^{* *}$ & $0.48^{* *}$ & & & \\
5. Shared Goal & 3.55 & 0.77 & $0.57^{* *}$ & $0.53^{* *}$ & $0.54^{* *}$ & $0.58^{* *}$ & & \\
6. Shared Norms & 3.25 & 0.93 & $0.46^{* *}$ & $0.31^{* *}$ & $0.32^{* *}$ & $0.32^{* *}$ & $0.37^{* *}$ & \\
7. Innovation Performance & 3.61 & 0.74 & $0.45^{* *}$ & $0.56^{* *}$ & $0.39^{* *}$ & $0.53^{* *}$ & $0.52^{* *}$ & $0.31^{* *}$ \\
\hline$* * p<0.01$ & & & & & & & &
\end{tabular}

$* * \mathrm{p}<0.01$.

Table 4 presented the results of the regression analysis. The six components explained the $96 \%$ variance of innovation performance in the total sample. Table 4 showed that $\operatorname{IOC}(\beta=0.01$, n.s.), and $\operatorname{IFC}(\beta=0.37, p<0.01)$, thereby partially supporting H1. Moreover, we found that IOT $(\beta=0.10, p<0.05), \mathrm{CO}(\beta=0.27, \mathrm{p}<0.01)$, SG $(\beta=0.18, p<0.01)$, and $\mathrm{SN}(\beta=0.07, \mathrm{p}<0.05)$, which support $\mathrm{H} 2$ and $\mathrm{H} 3$.

We further conducted a separate regression analysis for manufacturing and service organizations. Table 4 showed that the six components play different roles in improving innovation performance between the two industries. Only IFC ( $\beta=0.40, p<0.01$ for manufacturing industry; $\beta=0.35, p<0.01$ for service industry) and $\mathrm{CO}(\beta=0.10$, $\mathrm{p}<0.05$ for manufacturing industry; $\beta=0.32, \mathrm{p}<0.01$ for service industry) play significant roles in improving innovation performance in both manufacturing and service industries. What's more, $\operatorname{SG}(\beta=0.25, \mathrm{p}<0.01)$ improve innovation performance in the manufacturing industry, whereas it is not significant for service industry.

Table 4. Path coefficients

\begin{tabular}{|c|c|c|c|c|c|c|c|}
\hline & $\mathbf{R 2}$ & IOC & IFC & IOT & $\mathrm{CO}$ & SG & SN \\
\hline Total & 0.96 & 0.01 & $0.37 * *$ & $0.10^{*}$ & $0.27 * *$ & $0.18 * *$ & $0.07 *$ \\
\hline I. Manufacturing & 0.98 & -0.01 & $0.40 * *$ & 0.09 & $0.10 *$ & $0.25 * *$ & 0.07 \\
\hline II. Service & 0.98 & 0.01 & $0.35^{* *}$ & 0.10 & $0.32 * *$ & 0.13 & 0.08 \\
\hline
\end{tabular}

\subsection{The Coding of Social Capital Components into the NK Model}

According to the literature review and survey results, we finally identified IOC, IFC, IOT, CO, SG, SN as the fundamental elements of the system. The $N K$ model literature has suggested that the current organizational social capital components and the complexity of them are critical dependencies for future path search to higher ground of the rugged landscape (Ganco \& Hoetker, 2009; Fan \& Lee, 2012). So, we were in the hope of using empirical data as input to explore the initial condition and simulate possible outcomes for action planning (Frenken, 2006; Fan \& Lee, 2012). To develop this concept, we took the following approach: (i) to set the status of each component, (ii) identify the interdependency for each component, and (iii) address the unequal weights of the different components.

\subsection{Status of Each Component}

The constructs in this study were measured with multi-item scales (five-point Likert-type scales). The present and absent states were defined in finer detail according to a scale of five. Given that each search on the rugged landscape involves $A^{N}$ combinations, the spectrum of the search has $5^{6}=15625$ combinations, resulting in a 
significantly high computation effort. Therefore, we consider three status categories (instead of five): weak (1-2), average (3), and strong (4-5).

\subsection{Interdependency for Each Component}

The correlation matrix of the $n$ variables $\left(X_{1}, \ldots X_{n}\right)$ is an $n \times n$ matrix where the entry on position $(i, j)$ is $r_{i j}$, which represents the correlation coefficient between variables $i$ and $j$. Given the correlation matrix of the components, the summation for individual component $i$ for all $j$ not equal to $i$, represents the total value of the interdependency of component $i$ with all the other components. Thus, the efficacy of component $i$ depends not only on the choice concerning the single operational status $x_{i}$ but also on how the interdependency with the other components is resolved. Moreover, $K$ originally refers to epistasis among genes in the genotype of a species, reflecting a common attribute of the species (Kauffman, 1993). Previous literature has posited that organizational social capital is organizational endogenous resource which is industry-specific (Walker et al., 1997). Thus, taking into account that the interdependencies posed by organizational social capital components of an organization, we calculate the interdependency for each component with respect to manufacturing industry and service industry, respectively.

We utilized $K(\mathrm{IOC}), K(\mathrm{IFC}), K(\mathrm{IOT}), K(\mathrm{CO}), K(\mathrm{SG})$, and $K(\mathrm{SN})$ in the refined $N K$ model to denote the interdependency for inter-organizational coordination, inter-functional coordination, inter-organizational trust, customer orientation, shared goal, and shared norms, respectively. $K(\mathrm{IOC}), K(\mathrm{IFC}), K(\mathrm{IOT}), K(\mathrm{CO}), K(\mathrm{SG})$, and $K(\mathrm{SN})$ were employed to modify fixed integer $K$ in the $N K$ model. $K(\mathrm{IOC}), K(\mathrm{IFC}), K(\mathrm{IOT}), K(\mathrm{CO}), K(\mathrm{SG})$, and $K(\mathrm{SN})$ as well as the average complexity of the components within manufacturing and service industries are shown in Table 5.

Table 5. Interdependency for each component and average complexity

\begin{tabular}{llllllll}
\hline & $\boldsymbol{K}(\mathbf{I O C})$ & $\boldsymbol{K}(\mathbf{I F C})$ & $\boldsymbol{K}(\mathbf{I O T})$ & $\boldsymbol{K}(\mathbf{C O})$ & $\boldsymbol{K}(\mathbf{S G})$ & $\boldsymbol{K}(\mathbf{S N})$ & $\begin{array}{l}\text { Average } \\
\text { Complexity }\end{array}$ \\
\hline I. Manufacturing & 2.57 & 2.33 & 2.18 & 2.37 & 2.59 & 1.82 & 2.31 \\
II. Service & 2.59 & 2.38 & 2.36 & 2.49 & 2.59 & 1.78 & 2.36 \\
\hline
\end{tabular}

\subsection{Unequal Weights of Different Organizational Social Capital Components}

We assumed that $w(\mathrm{IOC}), w(\mathrm{IFC}), w(\mathrm{IOT}), w(\mathrm{CO}), w(\mathrm{SG})$, and $w(\mathrm{SN})$ are the weighted contributions of IOC, IFC, IOT, CO, SG, and SN, respectively. Table 4 showed that IFC, CO, and SG are significantly related to innovation performance in manufacturing industry, whereas the other components do not directly influence innovation performance. Thus, we considered ( $w(\mathrm{IOC}), w(\mathrm{IFC}), w(\mathrm{IOT}), w(\mathrm{CO}), w(\mathrm{SG}), w(\mathrm{SN}))=(0,0.40,0$, $0.10,0.25,0)$. For CS, SS, IC, and RS, we assigned zero to the path coefficients as their significance level $>0.05$. Based on a similar study, we deduced the weighted contributions of the six components for the two industries (Table 6).

Table 6. Unequal weights of the six components

\begin{tabular}{lllllll}
\hline & $w($ IOC $)$ & $w($ IFC $)$ & $w($ IOT $)$ & $w($ CO) & $w($ SG $)$ & $w($ SN $)$ \\
\hline I. Manufacturing & 0 & 0.40 & 0 & 0.10 & 0.25 & 0 \\
II. Service & 0 & 0.35 & 0 & 0.32 & 0 & 0 \\
\hline
\end{tabular}

Together with $N=6$ and $A=3$, the current status and unequal weights of the six components, and the interdependency for each component have been identified. Therefore, the initial parameters of the refined $N K$ model were prepared.

\section{Simulation Results}

Our model simulated the rugged fitness landscape, wherein organizations move about with a simple goal of increasing innovation performance. Particularly, the rugged landscape was determined by the interdependencies among the six components of organizational social capital. Figure 2(a) showed the maximum, minimum, and average innovation performance of the adaptive evolution for manufacturing organizations. Similarly, Figure 3(a) illustrated the analyzed graphs of maximum, minimum, and average innovation performance of the adaptive evolution for service organizations. 
The graphs of "Fraction still walking" for the agents in manufacturing and service industries were illustrated in Figures 2(b) and 3(b). The agents in manufacturing industry reached the sticking points within a period of 23 units, and those in service industry within 30 units. This result suggested that industrial type have varying influence on the adaptive evolution of innovation performance.
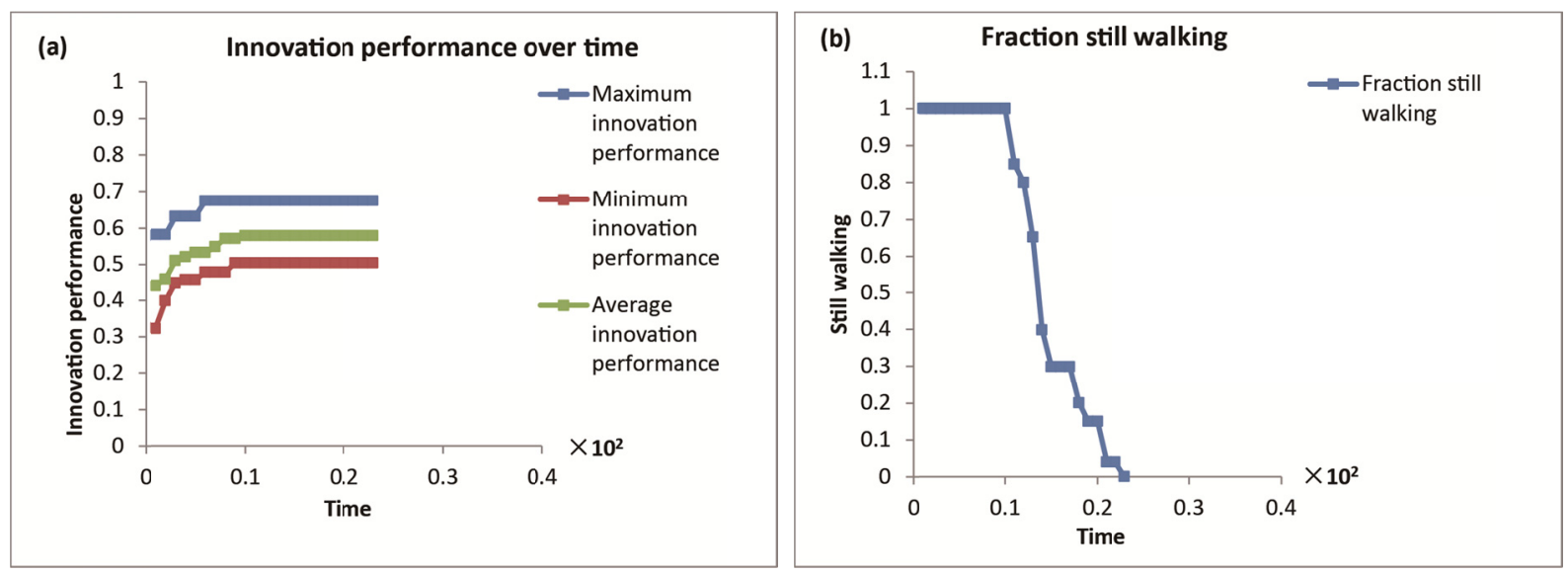

Figure 2. Search for manufacturing organizations
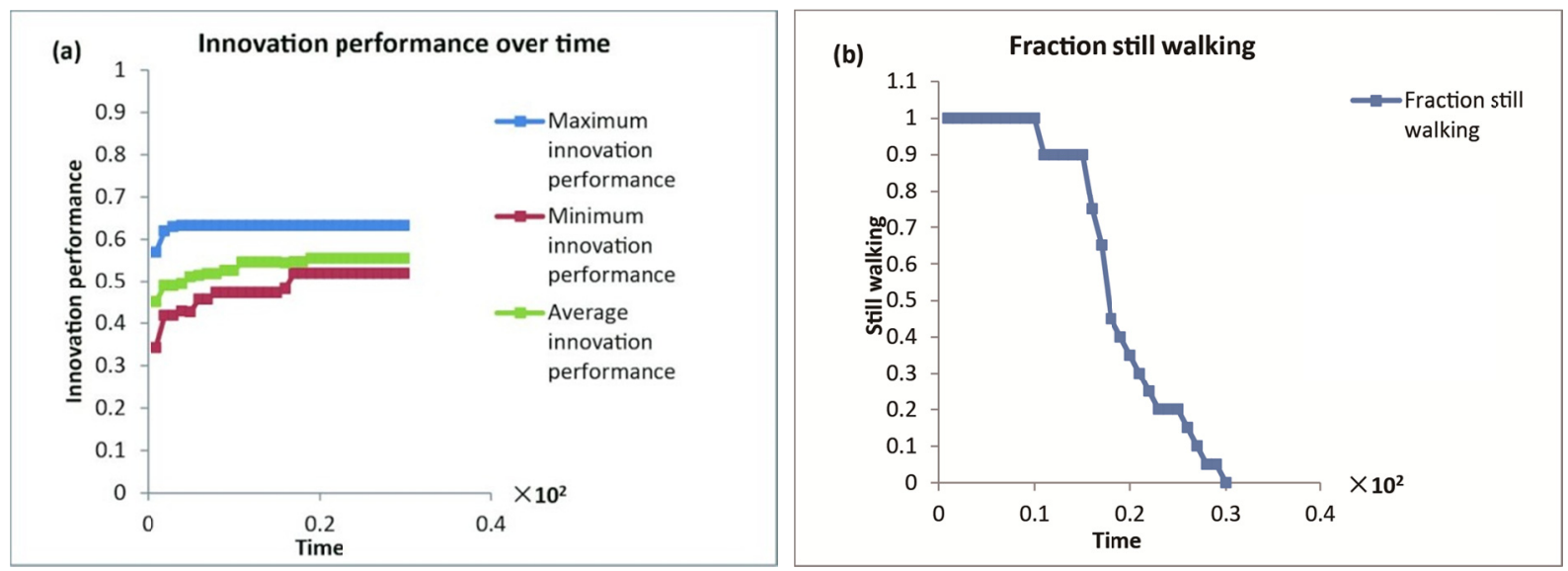

Figure 3. Search for service organizations

We further summarized the simulation results in Table 7. Table 7 showed that after stopping adaptive evolution, average innovation performance is 0.60 for manufacturing organizations, and 0.55 for service organizations. Hence, organizations in the two industries have different values of average innovation performance after stopping adaptive evolution. This finding suggested that in terms of adaptive evolution, manufacturing organizations are more conducive for the cultivation of organizational innovation.

Table 7. Maximum, minimum, average innovation performance, and performance range

\begin{tabular}{lllll}
\hline & $\begin{array}{l}\text { Average innovation } \\
\text { performance }\end{array}$ & $\begin{array}{l}\text { Maximum } \\
\text { innovation } \\
\text { performance }\end{array}$ & $\begin{array}{l}\text { Minimum } \\
\text { innovation } \\
\text { performance }\end{array}$ & $\begin{array}{l}\text { Innovation } \\
\text { performance range }\end{array}$ \\
\hline I. Manufacturing & 0.60 & 0.67 & 0.50 & 0.17 \\
II. Service & 0.55 & 0.63 & 0.52 & 0.11 \\
\hline
\end{tabular}

\section{Discussion}

Based on the CAS perspective, the current paper investigated the effects of organizational social capital on innovation performance. Specifically, by integrating survey study and the $N K$ model, we presented a refined $N K$ model to simulate the adaptive evolution of innovation performance on the rugged landscape, which is 
determined by the interdependencies among the components of organizational social capital. The research methods provide a systematic approach for the understandings of the interdependencies among the components of organizational social capital, and a strategic plan to enhance the organizational social capital in order to reach a higher innovation performance.

The correlation analysis revealed that the six components of organizational social capital are highly correlated, which indicates that these components are not only correlated theoretically but also interrelated empirically. The regression results showed that the six identified components have varying influence on organizational innovation performance and that some components have specific roles in different industries. For example, inter-functional coordination, inter-organizational trust, customer orientation, shared goal, and shared norms can act as critical characteristics for employee creativity, but inter-organizational coordination cannot. It is worth noting that shared goal positively affects organizational innovation performance for manufacturing industry but not significant for service industry. One possible explanation may relate to that organizations in Chinese manufacturing industry often face more rapid technological change and higher volatile market than those in service industry. For example, strategic alliance, the growth of outsourcing, and the expansion of supply chain is the lead firm's desire to achieve greater strategic flexibility and lower risk by reducing fixed investments, especially in manufacturing facilities (Sturgeon \& Lee, 2001). So, manufacturing firms versus service firms no longer have to carry the financial, administrative, and technical burdens of fixed capital related to production posed by shared goal. This point allows manufacturing firms can focus on innovation and become more organizationally and geographically flexible (Sturgeon, 2000).

The simulation results revealed that organizational innovation performance develops in different ways. Organizations in the manufacturing industry have the wider performance range than those in the service industry. This large variation among organizations in the energy industry is consistent with conventional wisdom. Innovations have become a commonplace in the administrative as well as the technical operations in organizations today (Han et al., 1998). Innovations are owing to more technical operations in manufacturing firms than in service firms. Nevertheless, in the environment of technological dynamics, organizations within manufacturing industry may easily show differential innovative performance.

As simulation results mentioned, average innovation performance in manufacturing organizations is higher than that in service organizations. This result is consistent with conventional wisdom. The degree of technological dynamics in the manufacturing industry in China is higher than that in the service industry. A high degree of technological dynamics creates a competitive environment, which in turn strengthens the competitive cognition of firms and improves their innovative strategy. On the other hand, much more spreading co-operational forms in manufacturing industry, such as supply chain and outsource, is favorable for spreading knowledge and information. Organizations within manufacturing industry can thus enhance their innovation performance through learning. Prior evidence also suggested that organizations with strategic alliance often display better effectiveness, productivity, reputation, morale, profit maximization, and stability than those with less values overlap (Posner et al., 2006).

\subsection{Theoretical Implications}

This study has several theoretical implications. First, in contrast with organizational social capital-based innovation literature that define organizational innovation as a static outcome, our research proposes organizational innovation as a CAS that reflects the evolution of organizational innovation performance. We investigated the adaptive process of organizational innovation performance through the NK model. This simulation approach may be superior to empirical one as a way to qualitatively disentangle the population, agent-level and environmental effects (Ganco \& Hoetker, 2009). Our research addresses the need for further technology management and complexity research on organizational innovation (Giannoccaro, 2011).

Second, we identified six components of organizational social capital, namely, inter-organizational coordination, inter-functional coordination, inter-organizational trust, customer orientation, shared goal, and shared norms. We empirically supported the direct relationship between these components and organizational innovation performance. Our findings indicated that these components are interdependent but affect innovation performance differently. For example, our result cannot support that inter-functional coordination affects innovation performance. Further, the influence of a same component on organizational innovation performance varies with the industry type. For example, although shared goal is critical for the manufacturing industry, it does not play a role in the service industry. These findings indicated that simultaneously considering various organizational social capital components is meaningful in the process of improving organizational innovation performance.

Third, our study addresses an issue on optimality in the NK modeling technique: organization may not attain the 
global optimum if they are provided full discretion over combinations of the components. Full discretion relaxes the constraints of myopia and allows the skipping of small trial-and-error steps by traversing the search space (Giannoccaro, 2011), thereby adding the possibility to obtain the global optimum of the rugged landscape. However, global optimum is also influenced by the attributes of the search space. The meaning and applicability of the combination of organizational social capital components may be restricted. For example, a value of zero in an $A=3$ situation may mean a weakening of customer orientation, whereas a value of zero in an $A=7$ situation may mean the total removal of customer orientation. The latter is both detrimental and unattainable. Therefore, awareness of context constraints is critical for organizational strategy to assess the value and utility of the generated adaptive behavior.

To our knowledge, our study breaks new ground in NK model application literature by comparing different types of organizations and industries. This comparison provides further evidence for the potential of the NK model.

\subsection{Practical Implications}

This study also leads to some practical implications. First, this study helps managers understand the components of organizational social capital. Our conceptualization of the three categories of components can help managers understand employee creativity systematically.

Second, our findings guide managers in selecting suitable organizational social capital components to improve organizational innovation performance. If managers enhance to communicate with customers leading to knowledge sharing and specialization, it will bring up innovation capability of their firms. Managers should realize that in the manufacturing and service industries, inter-functional coordination and customer orientation can be utilized to anticipate organizational innovation performance. Besides, managers in the manufacturing industry should pay attention to join in strategic alliance where members with shared goal may help the organization easily obtain acquirements to innovate.

Lastly, our simulation findings provide managers guidelines on how to improve organizational innovation performance from the CAS perspective. Our findings suggest that the process of improving organizational innovation performance is an iterative trial-and-error recombinant search, which means that all the organizational social capital components should be combined with dynamic balance. This finding implies that organizations possessing multiple strategic mechanisms might have an adaptive advantage over those who possess only a single mechanism. The acquisition of multiple strategic mechanisms may be enhanced through training programs that focus on organizational innovation-related methods or processes. For example, through training programs, managerial cognition of advantages of having multiple strategic mechanisms may be promoted. This could help them understand the role of these mechanisms in promoting their organizational innovation capabilities.

\subsection{Limitations and Future Research}

With regard to the generalizability of our results, there are some limitations that are worthy of discussion. First, we collected data with a single informant from each firm. Their individual perceptions may not accurately represent practical circumstance of organizational social capital and innovation performance of their firms. Future work should collect data from multiple informants.

Second, this study focused on only organizational social capital. Other substantial factors should be integrated into the NK model for strategy planning in future research. Aside from its contribution as a model and simulation method for organizational innovation, the NK model can also be applied in parallel simulations.

Finally, the NK model was developed primarily to approximate blind biological evolution. Hence, the model has limited applicability to the evolutionary process of innovation performance because managerial cognition plays an important role in the search strategy on the rugged landscape (Rivkin \& Siggelkow, 2007). Future studies should set specific boundaries and criteria for the path search.

\section{References}

Akçomak, I. S., \& Ter Weel, B. (2006). Social Capital, Innovation and Growth: Evidence from Europe. UNU-MERIT Working Paper 2006-040.

Butler, B., \& Purchase, S. (2008). Use of social capital among Russian managers of a new generation. Industrial Marketing Management, 37(5), 531-538. https://doi.org/10.1016/j.indmarman.2007.09.013

Carey, S., Lawson, B., \& Krause, D. R. (2011). Social capital configuration, legal bonds and performance in buyer-supplier relationships. Journal of Operations Management, 29(4), 277-288. https://doi.org/10.1016/j.jom.2010.08.003

Chow, W. S., \& Chan, L. S. (2008). Social network, social trust and shared goals in organizational knowledge 
sharing. Information \& Management, 45(7), 458-465. https://doi.org/10.1016/j.im.2008.06.007

Das, T. K., \& Teng, B. S. (2001). Trust, control, and risk in strategic alliances: An integrated framework. Organization Studies, 22(2), 251-283. https://doi.org/10.1177/0170840601222004

De Carolis, D., \& Saparito, P. (2006). Social capital, cognition, and entrepreneurial opportunities: A theoretical framework. Entrepreneurship Theory and Practice, 30(1), 41-56. https://doi.org/10.1111/j.1540-6520.2006.00109.x

Dosi, G., Faillo, M., Marengo, L., \& Moschella, D. (2011). Modeling routines and organizational learning. A discussion of the state-of-the-art (LEM Papers Series 2011/04). Pisa, Italy: Laboratory of Economics and Management (LEM), Sant' Anna School of Advanced Studies.

Dyer, J. H., \& Nobeoka, K. (2000). Creating and managing a high-performance knowledge-sharing network: the

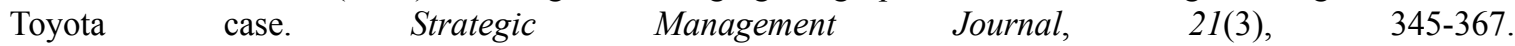
https://doi.org/10.1002/(SICI)1097-0266(200003)21:3<345::AID-SMJ96>3.0.CO;2-N

Fan, I. Y. H., \& Lee, R. W. B. (2012). Design of a weighted and informed NK model for intellectual capital-based innovation planning. Expert Systems with Applications, 39(10), 9222-9229. https://doi.org/10.1016/j.eswa.2012.02.083

Frenken, K. (2001). Modelling the organization of innovative activity using the NK-model. Nelson-and-Winter Conf., Aalborg, Denmark, 1-24.

Frenken, K. (2006). A fitness landscape approach to technological complexity, modularity, and vertical disintegration. Structural Change and Economic Dynamics, 17(3), 288-305. https://doi.org/10.1016/j.strueco.2006.01.001

Fukuyama, F. (1995). Trust: The social virtues and the creation of prosperity. New York: Free Press.

Ganco, M., \& Hoetker, G. (2009). NK Modeling Methodology in the Strategy Literature: Bounded Search on a Rugged Landscape. In Ketchen, D., Bergh, D. (Eds.), Research Methodology in Strategy and Management, 5, 237-268. https://doi.org/10.1108/S1479-8387(2009)0000005010

Giannoccaro, I. (2011). Assessing the influence of the organization in the supply chain management using NK simulation. Int. J. Production Economics, 131, 263-272. https://doi.org/10.1016/j.ijpe.2010.11.001

Goldstein, J. A., Hazy, J. K., \& Lichtenstein, B. B. (2007). Complex systems leadership theory: New perspectives from complexity science on social and organizational effectiveness. Mansfield, Mass: ISCE Pub.

Han, J.K., Kim, N., \& Srivastava, R.K. (1998). Market orientation and organizational performance: is innovation a missing link? Journal of Marketing, 62(4), 30-45. https://doi.org/10.2307/1252285

Hausera, C., Tappeinera, G., \& Waldeb, J. (2007). The Learning Region: The Impact of Social Capital and Weak Ties on Innovation. Regional Studies, 41(1), 75-88. https://doi.org/10.1080/00343400600928368

Huang, J.W., \& Li, Y.H. (2009). The mediating effect of knowledge management on social interaction and innovation performance. International Journal of Manpower, 30(3), 285-301. https://doi.org/10.1108/01437720910956772

Ibarra, H. (1993). Network centrality, power, and innovation involvement: determinants of technical and administrative roles. Academy of Management Journal, 36(3), 471-501. https://doi.org/10.2307/256589

Inkpen, A. C., \& Tsang, E. W. K. (2005). Social capital, networks, and knowledge transfer. Academy of Management Review, 30(1), 146-165. https://doi.org/10.5465/AMR.2005.15281445

Jamali, D., Yianni, M., \& Abdallah, H. (2011). Strategic partnerships, social capital and innovation: accounting for social alliance innovation. Business Ethics: A European Review, 20(4), 375-391. https://doi.org/10.1111/j.1467-8608.2011.01621.x

Kaasa, A. (2009). Effects of different dimensions of social capital on innovative activity: Evidence from Europe at the regional level. Technovation, 29(3), 218-233. https://doi.org/10.1016/j.technovation.2008.01.003

Kauffman, S. A. (1993). The origins of order: Self organization and selection in evolution. New York: Oxford University Press.

Lai, C. S. (2009). The use of influence strategies in interdependent relationship: The moderating role of shared norms and values. Industrial Marketing Management, 38, 426-432. https://doi.org/10.1016/j.indmarman.2008.06.003 
Landry, R., Amara, N., \& Lamari, M. (2002). Does social capital determine innovation? To what extent? $\begin{array}{lllll}\text { Technological Forecasting } \& \text { Social Change, 69(7), } & \text { 681. }\end{array}$ https://doi.org/10.1016/S0040-1625(01)00170-6

Levinthal, D., \& Warglien, M. (1999). Landscape Design: Designing for Local Action in Complex Worlds. Organization Science, 10(3), 342-357. https://doi.org/10.1287/orsc.10.3.342

Li, D., Chau, P. Y. K., \& Lai, F. (2010). Market Orientation, Ownership Type, and E-Business Assimilation: Evidence from Chinese Firms. Decision Sciences, 41(1), 115-145. https://doi.org/10.1111/j.1540-5915.2009.00261.x

Martínez-Cañas, R., Sáez-Martínez, F.J., \& Ruiz-Palomino, P. (2012). Knowledge acquisition's mediation of social capital-firm innovation. Journal of Knowledge Management, 16(1), 61-76. https://doi.org/10.1108/13673271211198945

Nahapiet, J., \& Ghoshal, S. (1998). Social capital, intellectual capital, and the organizational advantage. Academy of Management Journal, 23, 242-266.

Naranjo-Valencia, J.C., Jiménez-Jiménez, D., \& Sanz-Valle, R. (2011). innovation or imitation? The role of organizational culture. Management Decision, 49(1), 55-72. https://doi.org/10.1108/00251741111094437

Narver, J. C., \& Slater, S. F. (1990). The effect of a market orientation on business profitability. Journal of Marketing, 54(October), 20-35. https://doi.org/10.2307/1251757

Pérez-Luño, A., Medina, C. C., Lavado, A. C., \& Rodríguez, G. C. (2011). How social capital and knowledge affect innovation. Journal of Business Research, 64(12), 1369-1376. https://doi.org/10.1016/j.jbusres.2011.01.014

Posner, B. Z., Kouzes, J. M., \& Schmidt, W. H. (2006). Shared values make a difference: An empirical test of corporate culture. Human Resource Management, 24(3), 293-309. https://doi.org/10.1002/hrm.3930240305

Powell, W. W. (1996). Inter-organizational collaboration in the biotechnology industry. Journal of Institutional and Theoretical Economics, 152(1), 197-215.

Rivkin, J.W, \& Siggelkow, N. (2007). Patterned interactions in complex systems: Implications for exploration. Management Science, 53(7), 1068-1085. https://doi.org/10.1287/mnsc.1060.0626

Sørensen, J. B., \& Stuart, T. E. (2000). Aging, obsolescence, and organizational innovation. Administrative Science Quarterly, 45(1), 81-112. https://doi.org/10.2307/2666980

Stock, G. N., McFadden, K. L., \& Gowen, C. R. (2007). Organizational culture, critical success factors, and the reduction of hospital errors. International Journal of Production Economics, 106(2), 368-392. https://doi.org/10.1016/j.jpe.2006.07.005

Stock, G. N., \& Tatikonda, M. V. (2008). The joint influence of technology uncertainty and interorganizational interaction on external technology integration success. Journal of Operations Management, 26, 65-80. https://doi.org/10.1016/j.jom.2007.04.003

Sturgeon, T. J. (2000). Turn-key production networks: the organizational de-linking of production from innovation. In U. Jürgens (Ed.), New Product Development and Production Networks, Berlin: Springer-Verlag. https://doi.org/10.1007/978-3-662-04255-7_4

Sturgeon, T., \& Lee, J. R. (2001). Industry Co-Evolution and the Rise of a Shared Supply-Base for Electronics Manufacturing. Paper Presented at Nelson and Winter Conference, Aalborg, June.

Tamaschke, L. (2003). The role of social capital in regional technological innovation: seeing both the wood and the trees. In: Huysman, M., Wenger, E., Wulf, W. (Eds.), Communities and Technologies. Kluwer BV, Deventer. https://doi.org/10.1007/978-94-017-0115-0_13

Taylor, J., \& Levitt, R. E. (2005). Inter-organizational knowledge flow and innovation diffusion in project-based industries, 38th International Conference on System Sciences, IEEE Computer Society, Hawaii, USA. https://doi.org/10.1109/hicss.2005.334

Valente, M., Ciarli, T., Leoncini, R., \& Montresor, S. (2011). Linking technological change to organisation dynamics: Some insights from a pseudo-NK model. In N. De Liso \& R. Leoncini (Eds.), Internationalization, technological change, and the theory of the firm. London; New York: Routledge.

Walker, G., Kogut, B., \& Shan, W. (1997). Social capital, structural holes and the formation of an industry network. Organization Science, 8(2), 109-125. https://doi.org/10.1287/orsc.8.2.109 
Weerawardena, J., O’Cass, A., \& Julian, C. (2006). Does industry matter? Examining the role of industry structure and organizational learning in innovation and brand performance. Journal of Business Research, 59(1), 37-45. https://doi.org/10.1016/j.jbusres.2005.02.004

Willcocks, L., \& Choi, C. J. (1995). Co-operative partnership and 'total' IT outsourcing: from contractual obligation to strategic alliance? European Management Journal, 13(1), 67-78. https://doi.org/10.1016/0263-2373(94)00059-G

Wu, W. P. (2008). Dimensions of Social Capital and Firm Competitiveness Improvement: The Mediating Role of Information Sharing. Journal of Management Studies, 45(1), 122-146.

\section{Copyrights}

Copyright for this article is retained by the author(s), with first publication rights granted to the journal.

This is an open-access article distributed under the terms and conditions of the Creative Commons Attribution license (http://creativecommons.org/licenses/by/4.0/). 